\title{
Acute kidney injury in a shepherd with severe malaria: a case report
}

This article was published in the following Dove Press journal: International Journal of Nephrology and Renovascular Disease II October 2016

Number of times this article has been viewed

\author{
Boushab Mohamed \\ Boushab' \\ Fatim-Zahra Fall-Malick ${ }^{2}$ \\ Mamoudou Savadogo 3 \\ Leonardo Kishi Basco ${ }^{4}$ \\ 'Department of Internal Medicine, \\ Aïoun Regional Hospital, Hodh \\ El Gharbi, Mauritania; ${ }^{2}$ National \\ Institute of Hepatology-Virology \\ in Nouakchott, School of Medicine, \\ Nouakchott, Mauritania; ${ }^{3}$ Department \\ of Infectious Diseases, University \\ Teaching Hospital Yalgado Ouédrago, \\ Ouagadougou, Burkina Faso; ${ }^{4}$ Research \\ Unit of Infectious and Tropical \\ Diseases, Institut de Recherche pour \\ le Développement (Research Institute \\ for Development), Aix-Marseille \\ University, Marseille, France
}

Correspondence: Boushab Mohamed Boushab

Medicine Interne, Centre Hospitalier d'Aïoun, BP 74, Hodh El Gharbi,

Mauritanie

Tel +22246749087

Email bboushab@gmail.com
Abstract: Malaria is one of the main reasons for outpatient consultation and hospitalization in Mauritania. Although four Plasmodium species, ie, Plasmodium (P.) falciparum, P. vivax, $P$. malariae, and $P$. ovale, cause malaria in Mauritania, recent data on their frequency is lacking. Since infections with $P$. falciparum generally result in serious disease, their identification is important. We report a case of oliguric renal injury associated with malaria in a 65-year-old shepherd. Clinical manifestations included anemia, oliguria, and elevated creatinine and urea. The rapid diagnostic test for malaria and microscopic examination of blood smears were positive for $P$. falciparum. On the basis of this, the patient was diagnosed as having acute kidney injury as a complication of severe malaria. The patient was treated for malaria with intravenous quinine for 4 days, followed by 3 days of oral treatment. Volume expansion, antipyretic treatment, and diuretics were administered. He also had two rounds of dialysis after which he partially recovered renal function. This outcome is not always the rule. Prognosis depends much on early diagnosis and appropriate supportive treatment.

Keywords: malaria, oliguric kidney injury, shepherd, quinine, dialysis

\section{Introduction}

Malaria is a disease caused by protozoan parasites of the genus Plasmodium $(P)$, (P. falciparum, P. vivax, P. malariae, P. ovale, and $P$. knowlesi) and is transmitted in endemic areas by female Anopheles mosquitoes. ${ }^{1,2}$ The disease is still a major cause of morbidity and mortality in many tropical developing countries. ${ }^{2}$ In Mauritania, despite the lack of reliable health data, malaria is often considered as the third cause of medical consultation and hospitalization, after infectious diarrhea and acute respiratory diseases, in eight of 13 regions. ${ }^{3}$ Severe life-threatening complications, such as cerebral malaria, severe anemia, acidosis, jaundice, acute kidney injury, acute respiratory distress syndrome, pulmonary edema, and disseminated intravascular coagulation, occur mostly with $P$. falciparum infection. ${ }^{4}$ Few reports have appeared indicating an association of severe complications of malaria with $P$. vivax infection. ${ }^{5,6}$ We report a case of a patient presenting with severe malaria and acute kidney injury.

\section{Case report}

A 65-year-old shepherd residing in a malaria-endemic area in Mauritania (Kobeni, Hodh El Gharbi) with no remarkable history of renal disease presented with fever associated with chills, myalgia, vomiting, and loss of consciousness on September 2, 2015. The patient developed a flu-like syndrome (fever, headache, and arthralgia) 
and abdominal pain 3 days before hospitalization in Aïoun hospital (reference hospital of Hodh El Gharbi region). Clinical examination on admission showed severe impairment of consciousness with a Glasgow score of 8 , jaundice, dyspnea, and pallor. He had no rashes, edema, or palpable lymph nodes. The patient had hypotension $(60 / 40 \mathrm{mmHg})$, tachycardia, tachypnea ( 38 breaths $/ \mathrm{min}$ ), and hyperthermia $\left(40.5^{\circ} \mathrm{C}\right)$. The rapid diagnostic test for malaria and microscopic examination of blood smears were positive for P. falciparum. Laboratory examinations showed the following results: hemoglobin, $7 \mathrm{~g} / \mathrm{dL}$; mean corpuscular volume, $87 \mathrm{fL}$; aspartate aminotransferase, $104 \mathrm{IU} / \mathrm{L}$; alanine aminotransferase, $93 \mathrm{IU} / \mathrm{L}$; total bilirubin, $49 \mu \mathrm{mol} / \mathrm{L}$; direct bilirubin, $77 \mu \mathrm{mol} / \mathrm{L}$; and random blood glucose, $1.02 \mathrm{~g} / \mathrm{L}$. Urinalysis and cerebrospinal fluid tests were negative.

On the second day of hospitalization, the patient developed shortness of breath with no cough and anuria (with only $50 \mathrm{~mL}$ urine collected over 24 hours); this was soon followed by hiccups. A chest X-ray was performed, which helped confirm a diagnosis of pulmonary edema. The renal workup revealed serum creatinine of $102 \mathrm{mg} / \mathrm{dL}$, serum urea of $1.17 \mathrm{~g} / \mathrm{L}$ (high), serum potassium of $5.1 \mathrm{mEq} / \mathrm{L}$, and serum sodium of $142 \mathrm{mEq} / \mathrm{L}$. On the basis of these results, the patient was diagnosed as having severe malaria with acute kidney injury, pulmonary edema, and anemia. The patient was admitted to the hemodialysis unit for emergency dialysis. Quinine (10 mg/kg body weight) was administered every 8 hours in $5 \%$ dextrose infusion for 4 days. Volume expansion, antipyretic treatment, and diuretics were administered. After two sessions of consecutive hemodialysis of $4 \mathrm{~h} / \mathrm{d}$, the patient became conscious and had urine output of $1900 \mathrm{~mL} / 24 \mathrm{~h}$. Serum creatinine, urea, and potassium were $29 \mathrm{mg} / \mathrm{dL}, 0.47 \mathrm{~g} / \mathrm{L}$, and $4 \mathrm{mEq} / \mathrm{L}$, respectively. The patient was discharged from the hospital 4 days later in good health. The follow-on oral treatment was a full course of artesunatesulfamethoxypyrazine-pyrimethamine (Co-arinate FDC ${ }^{\circledR}$; Dafra Pharma, Turnhout, Belgium) for 3 days. The patient was closely followed up after 3 weeks and was found to have normal and stable renal function, and he was also asymptomatic. Adjuvant therapy was prescribed, and no control blood smear for malaria parasites was made.

\section{Discussion}

This observation illustrates a manifestation of severe malaria rarely reported in an autochthonous adult. Acute kidney injury is, however, well known in adults and, in particular, in nonimmune subjects with P. falciparum malaria infections. ${ }^{2,7}$ Furthermore, $P$. falciparum is recognized as an important cause of acute kidney injury in areas of intense transmission. ${ }^{4}$ The incidence of malarial acute kidney injury worldwide is $1-4 \%$ and may be as high as $60 \%$ among nonimmune adults from nonendemic regions visiting malaria-endemic regions of the world ${ }^{8}$ The pathogenesis of acute kidney injury in malaria is still not clearly understood. Blockage of renal microcirculation due to sequestration of infected erythrocytes, immune-mediated glomerular injury and volume depletion are some of the proposed hypotheses. ${ }^{9}$ The diagnosis of acute kidney injury has been established on the basis of clinical evidence (anuria) and biochemical characteristics (azotemia, hyponatremia, and hypokalemia). 2,7,10 The reported polyuria is a classic evolution of diuresis during treatment of acute kidney injury and is due to recovery from fluid retention, which may be likened to the removal of an obstacle. ${ }^{10}$ Hepatic involvement revealed by cytolysis has been reported by some authors. ${ }^{2,10}$ It is however generally mild and transient and resolves spontaneously and rapidly in a few days. ${ }^{10}$

Kidney injury in malaria involves several mechanisms. It may occur in case of circulatory insufficiency, but it may also be due to the precipitation of hemoglobin crystals in renal tubules during intravascular hemolysis. In case of high parasitemia, anoxic-ischemic lesions may be observed in connection with the phenomena of adhesion of $P$. falciparum trophozoite- and schizont-infected erythrocytes to the endothelium of renal capillaries. ${ }^{11}$ Malarial acute kidney injury can occur as an isolated complication or as a component of multiorgan involvement. ${ }^{2}$ Indeed, it should be suspected in the presence of anuria despite adequate rehydration, and the diagnosis is confirmed if serum creatinine is elevated, ${ }^{12}$ as was the case of our patient whose condition improved after hemodialysis. Although dialysis has significantly improved the management of acute kidney injury in severe malaria, prognosis remains poor. ${ }^{10}$ An appropriate treatment includes intravenous quinine (or if available, parenteral artesunate or artemether should be used in preference to quinine $)^{13}$ and diuretics, such as furosemide.

\section{Conclusion}

Acute kidney injury secondary to severe malaria is uncommon. The prognosis depends on early diagnosis and treatment. Rapid initiation of hemodialysis proves useful in the restoration of renal function.

\section{Consent}

Written informed consent for publication of the clinical details was obtained from the patient. A copy of the written consent is available for review by the Editor-in-Chief of this journal. 


\section{Author contributions}

Boushab Mohamed Boushab was involved in drafting the manuscript, made substantial contributions to study conception and design, helped in clinical data verification, and gave input for the "Discussion" section. Fatim-Zahra Fall-Malick, Mamoudou Savadogo, and Leonardo Kishi Basco contributed to manuscript correction. All authors contributed toward data analysis, drafting and critically revising the paper and agree to be accountable for all aspects of the work.

\section{Acknowledgments}

The authors would like to acknowledge the tireless efforts of all workers at the hemodialysis unit, for their good patient care together with the doctors and nurses of the Aïoun Regional Referral hospital, for their initial care of this patient and timely referral of the patient.

\section{Disclosure}

The authors report no conflicts of interest in this work.

\section{References}

1. Falade-Nwulia OO, Dhaliwal G, Schreiber MP, Saint S, Shorr AF. A 36-year-old Haitian man with coma, acute kidney injury, lactic acidosis, and respiratory failure. Chest. 2012;142(3):798-801.
2. Meremo AJ, Kilonzo SB, Munisi D, et al. Acute renal failure in a Caucasian traveler with severe malaria: a case report. Clin Case Rep. 2014;2(3):82-85.

3. Ould Ahmedou Salem MS, Basco LK, Ouldabdallahi M, et al. Malariaassociated morbidity during the rainy season in Saharan and Sahelian zones in Mauritania. Acta Trop. 2015;152:1-7.

4. Das BS. Renal failure in malaria. J Vector Borne Dis. 2008;45(2): 83-97.

5. Ozen M, Gungor S, Atambay M, Daldal N. Cerebral malaria owing to Plasmodium vivax: case report. Ann Trop Paediatr. 2006;26(2): 141-144.

6. Sarkar S, Bhattacharya P. Cerebral malaria caused by Plasmodium vivax in adult subjects. Indian J Crit Care Med. 2008;12(4):204-205.

7. Badiane AS, Diongue K, Diallo S, AB, et al. Acute kidney injury associated with Plasmodium malariae infection. Malar J. 2014;7;13:226.

8. Tangpukdee N, Elshiekh SB, Phumratanaprapin W, Krudsood S, Wilairatana P. Factors associated with acute renal failure in falciparum malaria infected patients. Southeast Asian J Trop Med Public Health. 2011;42(6):1305-1312.

9. Nguansangiam S, Day NP, Hien TT, et al. A quantitative ultrastructural study of renal pathology in fatal Plasmodium falciparum malaria. Trop Med Int Health. 2007;12:1037-1050.

10. Mabiala-Babela JR, Kaly-Ibala R, Ganga-Zandzou PS, Mouko A, Senga P. [Severe malaria associated with acute renal insufficiency: apropos of a case]. Bull Soc Pathol Exot. 2002;95(2):74-75. French.

11. Prakash J, Gupta A, Kumar O, Rout SB, Malhotra V, Srivastava PK. Acute renal failure in falciparum malaria--increasing prevalence in some areas of India - a need for awareness. Nephrol Dial Transplant.1996;11(12):2414-2416.

12. Abdul Manan J, Ali H, Lal M. Acute renal failure associated with malaria. J Ayub Med Coll Abbottabad. 2006;18(4):47-52.

13. World Health Organization. Guidelines for the Treatment of Malaria. 3rd ed. Geneva, Switzerland: World Health Organization; 2015.

\section{Publish your work in this journal}

The International Journal of Nephrology and Renovascular Disease is an international, peer-reviewed open access journal focusing on the pathophysiology of the kidney and vascular supply. Epidemiology, screening, diagnosis, and treatment interventions are covered as well as basic science, biochemical and immunological studies. The manuscript management system is completely online and includes a very quick and fair peer-review system, which is all easy to use. Visit http://www. dovepress.com/testimonials.php to read real quotes from published authors. 